\title{
Global \& Community Health: A perspective on neurologic care at Mulago Hospital in Uganda
}

Monica M. Diaz, MD

Neurology ${ }^{\circledR} 2019 ; 92: 579-581$. doi:10.1212/WNL.0000000000007149

Looking out from atop Uganda National Mosque's minaret, one of the highest points in Kampala, the capital city of Uganda, one sees winding narrow roads turning bright orange with rainfall converging to meet at the mosque in Old Kampala. These roads are congested with a lawless swirl of traffic involving pedestrians, matatus (communal taxis), and boda-bodas (motorbikes). There are women in colorful gomesis (traditional dress in the Buganda kingdom), men in dress shirts, and children selling fruit on the side of the roads, all working under the heat of the equatorial sun to bring life to this beautiful, chaotic city. As a resident in my second year of neurology training, I had the opportunity to visit and participate in care for this Ugandan community. I spent 6 weeks in Kampala on an international elective rotation coordinated through the Yale/Stanford Johnson \& Johnson Global Health Scholars Program at Mulago Hospital, an experience that enhanced my training as a neurologist and perspective as a clinician.

Uganda is a country of 39 million people with 40 spoken dialects, sitting on the shores of Lake Victoria in East Africa. It has earned the title of "The Pearl of Africa," with its lush vegetation, copious rainfall, and abundant wildlife. Despite these natural resources, only $26.7 \%$ of the population, mostly in urban areas, has access to electricity. ${ }^{1}$ Almost half of the population is under the age of 15, with a life expectancy of 59 years, and the average fertility rate is 6 children per Ugandan woman. ${ }^{2}$ Despite this, Uganda has reduced monetary poverty at a rapid rate, from $31.1 \%$ living below the national poverty line in 2006 to $19.7 \%$ in $2013 .{ }^{3}$

My experience in Kampala, Uganda, began on the neurology wards of Mulago Hospital, a public 1,500-bed facility that attends to 120,000 inpatients annually as the main tertiary referral center in Uganda. Each day we saw about 30-40 patients, all housed within 2 large rooms, divided into male and female wards. Hospital beds were pressed up next to each other, draped with colorful blankets brought from home (the hospital does not routinely provide sheets), without divider curtains as a refuge for privacy. The nurse to patient ratio is about 1 nurse to $20-30$ patients. An attendant (or caregiver who accompanies the patient from their home village) sits by the bedside on a straw mat and provides the most basic patient care, from toileting, feeding, and washing bedsheets, to going to pharmacies to purchase inpatient medications, to dispensing the medication to the patient.

The day begins with bedside rounds each morning with a hospitalist attending physician, a senior house officer (or resident), intern, and medical students. The hospital provides patient charts that are kept at bedside during their inpatient stay, which patients and attendants retain after discharge from the hospital. The patient is examined, the chart is reviewed on rounds, and a plan is formulated at the bedside. Much of the time is spent explaining the costs of medications, procedures, or imaging studies to the patient and attendant, as costs tend to be the factor that decides what care the patient can receive.

Only $2 \%$ of Ugandans have private health insurance; thus, the majority of personal health care expenses are paid out-of-pocket in cash at the time of hospital admission. Although health care in Uganda is free, patients must pay most expenses out-of-pocket in cash if not covered by the national health care system. Those who cannot pay must borrow money from family or sell

\section{Correspondence}

Dr. Diaz

Monicadiaz685@gmail.com

RELATED ARTICLE

An international exchange observership at Yale University: A Ugandan physician experience

Page 582 
possessions or petition the hospital to pay for their hospital stay. ${ }^{4,5}$ It is common for patients to spend 3-4 days in the casualty (or emergency department) prior to admission to the neurology ward. Few tests are provided for free, including complete blood count testing, immune suppression syndrome (the name given to HIV in Uganda) testing, chest X-ray, and lumbar puncture. A brain CT scan costs $\$ 100$ USD and an MRI brain about $\$ 500$ USD, and many patients cannot afford either. Mulago Hospital houses 2 CT scanners, both of which were nonfunctioning during my time there, so patients were referred to private hospitals to obtain a CT scan, sometimes using the hospital ambulance but often transported in a family member's personal vehicle. Four EEG machines are available, but there may not be personnel trained to read and interpret EEGs. Lumbar punctures are often performed once increased intracranial pressure is ruled out via a funduscopic examination (CT scans could take days to obtain). Critical care is limited. A 5-bed intensive care unit (ICU) exists in Mulago Hospital but beds are always occupied. A patient presenting in an obtunded state would have quickly been intubated and moved to a higher level of care in the Western world, but this is simply not possible without access to a ventilator and ICU. Patients in respiratory distress are placed on their side to prevent aspiration with an emergency oral airway in place, and the patient is connected to an oxygen tank shared with 5 other patients also in respiratory distress. Despite these drawbacks, Uganda has made advances in palliative care services, with nurses trained in assisting with end-of-life care on the wards. ${ }^{6}$

Because many resources are either not available or unable to be paid for, much of the assessment relies on the neurologic history and examination. The neurologic history is at times limited by a language barrier, with an attendant of another patient who speaks the patient's dialect often serving as interpreter. The neurologic examination is crucial given limited imaging studies available. A patient with HIV presenting with hemiparesis has either toxoplasmosis or a stroke until proven otherwise, and if no head CT can be obtained, then the patient is discharged on aspirin for stroke prevention and empiric toxoplasmosis treatment. Patients presenting obtunded and febrile with anemia are treated for cerebral malaria. A diagnosis of atrial fibrillation in a stroke patient is made by palpation of the radial pulse, and elevated intracranial pressure is ruled out by funduscopic examination. I evaluated patients with illnesses common in the United States, such as hemorrhagic and ischemic strokes, seizures, myasthenia gravis, Parkinson disease, and spinal cord compression. I also cared for patients with conditions less prevalent in the United States, such as toxoplasmosis, progressive multifocal leukoencephalopathy, tuberculous meningitis, neurocysticercosis, and cerebral malaria. Much of the infectious diseases ward contained patients with HIV-related opportunistic infections, meningitis, and tetanus (mostly unvaccinated people who had stepped on a nail and developed trismus, laying in beds under a black cover used to reduce stimuli). Many patients are discharged without a definitive diagnosis without the benefit of neuroimaging or EEG. The hospital provides few select medications for free, but in most instances, the required medications, which often are unaffordable, must be paid for in cash by the patient and patient's family. Available antiepileptic drugs include phenobarbital, carbamazepine and phenytoin, but antiepileptic drug levels are unavailable. Aspirin and antihypertensives are available for stroke prevention. IV mannitol may not be available in the hospital pharmacy and must be purchased from an outside pharmacy by the attendant.

Neurologic care in sub-Saharan Africa is often limited by the cultural stigma surrounding neurologic illness, scarcity of medications, inability to pay for tests, and inaccessibility to specialists. Neurologists are scarce throughout sub-Saharan Africa, with 1 neurologist for every 4 million people. ${ }^{7}$ Mulago Hospital has 1 neurologist on staff and most neurologic care is provided by internists. The role of a visiting neurology resident in a limited resourced setting can be unclear at times, but one important way to foster interest in neurology is to provide teaching of clinical neurology and neurologic examination findings to the local residents and medical students. Raising awareness of the importance of specialty training in neurology will help create a stronger interest in the field of neurology among Ugandan trainees, subsequently making a plea for development and funding of local neurology training programs. Neurology trainees can help by participating in an international rotation in an underresourced country. The Yale/Stanford Johnson \& Johnson Global Health Scholars program is available to internal medicine and emergency medicine residents in the United States, and was coordinated for neurology residents with the help of faculty in the Yale Department of Neurology and Makerere University in Kampala. The program has also sponsored visiting physicians from other countries to spend up to 1 year rotating on the neurology wards at Yale. The goal of programs such as these is to help achieve equality in medical as well as neurologic care throughout the world. Recently, a stronger interest has been expressed in global neurology exchange programs, many of these with longstanding exchange partnerships that help foster collaboration and education between the institutions. ${ }^{8}$ My Ugandan colleagues taught me how to diagnose infectious diseases underrecognized in the United States without the use of ancillary diagnostic tools, and shared a wealth of knowledge with me. My experience at Mulago Hospital was invaluable as it helped not only to refine my clinical skills as a neurologist, but also helped me to see neurology from a humble perspective.

\section{Study funding}

No targeted funding reported.

\section{Disclosure}

M.M. Diaz reports no disclosures relevant to the manuscript. Go to Neurology.org/N for full disclosures. 


\section{References}

1. The World Bank. Access to electricity (\% of population) [online]. Available at: dataworldbank.org/indicator/EG.ELC.ACCS.ZS?year_high_desc=false. Accessed April 24, 2018.

2. World Health Organization. Global health observatory country views. In: Uganda Statistics Summary (2002-present) [online]. Available at: apps.who.int/gho/data/ node.country.country-UGA. Accessed April 24, 2018.

3. The World Bank. Uganda poverty assessment 2016: fact sheet [online]. Available at: worldbank.org/ en/country/uganda/brief/uganda-poverty-assessment-2016-fact-sheet. Accessed April 24, 2018.

4. Zikusooka CM, Kyomuhang RL, Orem JN, Tumwine M. Will private health insurance schemes subscriptions continue after the introduction of National Health Insurance in Uganda? Afr Health Sci 2009;9:S66-S71.
5. Anderson GA, Ilcisin L, Kayima P, et al. Out-of-pocket payment for surgery in Uganda: the rate of impoverishing and catastrophic expenditure at a government hospital. PLoS One 2017;12:e0187293.

6. Downing J, Batuli M, Kivumbi G, et al. A palliative care link nurse programme in Mulago Hospital, Uganda: an evaluation using mixed methods. BMC Palliat Care 2016;15:40.

7. Atlas: Country Resources for Neurological Disorders, 2nd ed. Geneva: World Health Organization; 2017.

8. Samudralwar RD, Goss A, Rimmer K, et al. International issues: a guide to US academic global health programs in neurology. Neurology 2018;90: 662-665.

\section{Visit the Neurology ${ }^{\circledR}$ Website at Neurology.org/N}

- More article-based content on home pages

- Streamlined menus and navigation

- Enhanced blog sections for specialty areas

- Same experience on desktop, tablet, and mobile devices

- Audio summaries of current issues

- Improved article reading experience; links more evident (pdf, analytics, social media)

- Neurology ${ }^{\circledR}$ Clinical Practice initiative "Practice Current" global surveys will be accessible across sites

f Find Neurology ${ }^{\circledR}$ on Facebook: http://tinyurl.com/neurologyfan

Follow Neurology ${ }^{\circledR}$ on Twitter: https://twitter.com/GreenJournal

\section{New AAN Practice Management Webinar Format Digs Deeper}

The new format offers a live, 30- to 45-minute webinar with expert faculty followed by several shorter recorded online lectures that explore the topic in greater depth. Each topic concludes with a 30-minute live webchat for further participant Q\&A. Purchase a single webinar series for $\$ 99$ or purchase a 2019 Practice Management Webinar subscription for only \$189-that's less than $\$ 32$ per webinar!

\section{Webinar Series}

- January 15 - Boss, MD: Managing a Better Practice

- March 12 - Understanding How You Get Paid

- May 21 - Everything You Wanted to Know About Your Patients but Were Afraid to Ask: Having Difficult Conversations with Patients from Vulnerable Populations

- August 13 - Increasing Revenue in Your Practice: Care Models, Ancillary Services, and Other Strategies

- October 1 - Using Technology for Better Practice Management of Stroke

- November 19 - Seeing the Future Clearly: How to Succeed in 2020

Learn more and register at $A A N . c o m / v i e w / w e b i n a r$. 


\section{Neurology}

\section{Global \& Community Health: A perspective on neurologic care at Mulago Hospital in Uganda \\ Monica M. Diaz \\ Neurology 2019;92;579-581 \\ DOI 10.1212/WNL.0000000000007149}

This information is current as of March 18, 2019

\section{Updated Information \& Services}

References

Subspecialty Collections

Permissions \& Licensing

Reprints including high resolution figures, can be found at: http://n.neurology.org/content/92/12/579.full

This article cites 4 articles, 1 of which you can access for free at: http://n.neurology.org/content/92/12/579.full\#ref-list-1

This article, along with others on similar topics, appears in the following collection(s):

All global neurology

http://n.neurology.org/cgi/collection/all_global_neurology

Information about reproducing this article in parts (figures,tables) or in its entirety can be found online at:

http://www.neurology.org/about/about_the_journal\#permissions

Information about ordering reprints can be found online:

http://n.neurology.org/subscribers/advertise

Neurology ${ }^{\circledR}$ is the official journal of the American Academy of Neurology. Published continuously since 1951, it is now a weekly with 48 issues per year. Copyright @ 2019 American Academy of Neurology. All rights reserved. Print ISSN: 0028-3878. Online ISSN: 1526-632X.

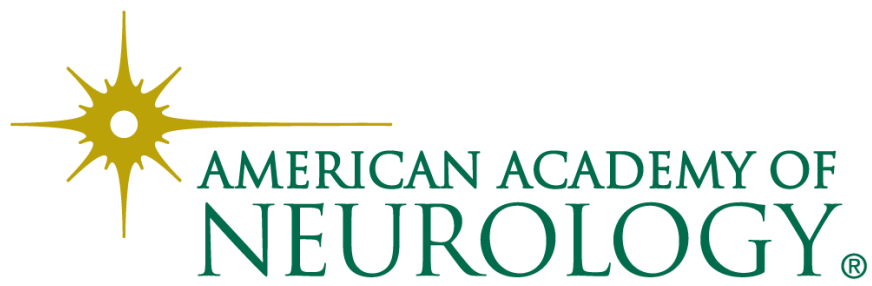

